\title{
EL DISCURSO INDIRECTO LIBRE EN LA NARRATIVA DE MIGUEL ANGEL ASTURIAS
}

\section{Mignon Dominguez de Rodríguez-Pasqués}

Hemos seleccionado dos novelas del escritor guatemalteco para estudiar las características que asume el DIL en su técnica narrativa. Dividimos el enfoque del DIL en dos tipos según que se reproduzca el habla de uno o de varios personajes, o se reproduzca el pensamiento. A la primera forma la denominamos $\mathrm{DIL}_{\mathrm{a}}$ y a la segunda, $\mathrm{DIL}_{\mathrm{b}}$.

Consideramos este recurso una forma de suma productividad en español, por la gran flexibilidad de la lengua. En esto aventaja indudablemente a la lengua francesa. Si Marguerite Lips, autora de la primera tesis sobre estilo indirecto libre, ${ }^{1}$ eximia discípula de Bally, pudo encontrar abundantes ejemplos de ese recurso en el francés medieval, no fueron menores los hallazgos de Friedrich Todemann, autor del primer estudio serio sobre DIL en español. ${ }^{2}$

El interés que esta forma reviste para la moderna literatura y para el análisis estilístico es inapreciable. Amplía los moldes adotados hasta el momento, permite observar matices desconocidos o características del escritor. En el caso de Asturias, sus novelas ganan con el empleo del DIL y a rompe la monotonía de la simple narración y quiebra con giro elegante la línea a veces demasiado rápida y objetiva del puro diálogo.

Asturias saca consciente o subconscientemente partido de esta innovación, unas veces para reproducir el habla de grupos, otras para ofrecer los matices psicológicos del habla individual.

\section{El señor presidente $(1946)^{-3}$}

Esta obra nace en Guatemala en 1922 en forma da cuento: "Los mendigos políticos." En París, el cuento se va agrandando. Asturias lo lee a sus amigos César Vallejo y Arturo Uslar Pietri. Archivado en 1930 aparece publicado em 1946 y lleva a su autor a la fama.

La novela es una sátira, descripción grotesca y expresionista. No aborda ciertamente un tema nuevo pero ningún libro logra como el suyo plena originalidad por la trascendencia que otorga a la dictadúra y la universalidad con que presenta un cuadro hispanoamericano no referido directamente a una persona y a un lugar.

Los primeros capítulos constituyen cuadros surrealistas y esperpénticos. Trabaja la novela con esta materia fea y repugnante: mendigos, borrachos, piojosos, adulones cobardes, hipócritas, y logra darle un tono poético. A la intención político social, une su fuerza literaria, su gusto estético, su indiscutido conocimiento de los mitos y religiones 
mayas reflejado a través de toda su obra. Esta gravitación de la literatura indígena se desarrolla en dos planos señalados por el mismo Asturias: "el del sueño y el de la realidad." Los textos indígenas retratan "la realidad de los sentidos pero comunican además una realidade onírica." 4

El dictador viene a representar la divinidad maya quiché, Tohil, que exigía sacri. ficios humanos. Es la visión que tiene Cara de Angel en el capítulo XXXVII, preanuncio de su muerte.

En el capítulo II la escena de la prisión donde atormentan a los mendigos para que confiesen lo que quiere el dictador, y no la verdad, Asturias nos ofrece un ejemplo interesante de DIL. Se trata de la reproducción del pensamiento no de una sola persona sino del pensar colectivo de los pordioseros:

Un quinqué mechudo alumbraba la estancia adonde les habian trasladado. Su luz débil parecia alumbrar a través de lentes de $\left[/ /=\mathrm{DIL}_{\mathrm{b}}\right]$ agua. / ¿En dónde estaban las cosas? ¿En dónde estaba el muro? ¿En dónde ese escudo de armas más armado que las mandibulas de un tigre $y$ ese cincho de policía con tiros de revólver? / (p. 15).

El arte el del novelista reside en que coloca en DIL el monólogo interior de los mendigos en tanto que opta por el discurso indirecto y por el directo cuando se trata de pregunta y respuesta.

En el sueño del pobrecito idiota Pelele cuando la Virgen sale a preguntarle qué quiere:

De un camarín - como pasa la luz por los cristales, no obstante el vidrio - salió la Virgen del Carmen a preguntarle qué quería, a quién buscaba...

Tan gran señora no media un metro pero cuando hablaba daba la impresión de entender de todo como la gente grande. Por señas le contó el Pelele lo mucho que le gustaba masticar cera y ella, entre seria y sonriente, le dijo que tomara una de las candelas encendidas del altar ... (p. 25).

Todo el sueño - la mitad del capítulo IV - está narrado em tercera persona con cortas irrupciones de diálogo, pero en el momento en que el Pelele, de la ternura que siente el soñar con su madre pasa a encontrarse con la Virgen y ésta le habla, la emoción es tan inefable que el autor la vierte en DIL: / "La felicidad completa! Sentíase feliz desde la puntitita de la lengua hasta la puntitita de los pies!"/ (p. 25). O sea el autor se introduce en el personaje, se adueña de su habla, en la ternura del diminutivo, y en la gracia del conjuro infantil. Destacamos la maestría de Asturias en el uso del $\mathrm{DIL}_{\mathrm{b}}$, porque lo presenta en el monólogo interior la única forma en que Pelele puede expresarse, ya que es mudo.

Un caso de reprodución del habla. En el capítulo VI el favorito Cara de Angel ha entrado a una taberna. Su propósito es demorarse: 
/ Tal vez la fondera no tenía vuelto./ [DIL $\left.\mathrm{D}_{\mathrm{b}}\right]$ Esta abrió el cajón de la venta con disgusto, hurgó entre los billetes mugrientos y lo cerró de golpe. / No tenía vuelto. Siempre la misma historia de salir a buscar cambio / (p. 39). [DIL $\left.\mathrm{D}_{\mathrm{a}}\right]$

En pocos renglones Asturias ha hecho hablar a dos personajes por medio del DIL, uno en su pensamiento, el otro en voz alta; él mismo ha intervenido en la narración como autor omnisciente.

Un caso de DIL coral en el desorden y la confusión que se produce ante un supuesto atentado contra el dictador. Leo Spitzer llamó DIL coral al discurso indirecto libre que reproduce el habla de varias o muchas personas.

Un coronel se perdio escalera arriba guardándose el revólver. Otro bajaba por una escalera de caracol guardándose el revólver. / No ena nada./ / i No era nada! Un capitán pasó por una ventana guardándose el revólver. Otro ganó una puerta guardándose el revólver. / No era nada./ / No era nada! / Pero el aire estaba frio. La noticia cundió por las salas en desorden. / No era nada / (p. 99).[DIL $]$

El DIL contribuye al carácter esperpéntico de la escena. En tres palabras se advierte claramente la función del recurso. En el último "No era nada" el sentido coral va unido a la técnica del eco.

\section{El Alhajadito (1961) ${ }^{6}$}

La novela se abre sugestiva, con un pespunte de interrogantes, en un oscuro corredor de una inmensa casona, donde se hacinan barricales con ceniza y viejas monedas. Sobre él se va a levantar el delirar onírico del alhajadito. Su fantasía va creciendo ante el silencio de los mayores. Todo se reconstruye para el sueño y por el sueño. Y con historia y sueño se va labrando un poema en prosa tan hermoso como Hombres de maiz en otro enfoque y particularidad estilística. En ese mundo misterioso, representado por la casona del alhajadito donde los criados indios de largas trezas obran como si cada noche fueran a volver los antepasados que se fueron, los motivos se dan, aparecen y desaparecen con la maravilla y el fulgor de los sueños.

El niño tiene el presentimiento de un mundo inexplorado, más allá de la realidad de las cosas. Asturias recurre al DIL en esta novela surrealista con más frecuencia que en la anterior caracterizada por su fuerte expresionismo.

Un tiznón de carbón en la pared que fue blanca, amaneció un dia como rajadura de temblor...

¿¿Quién tinó la pared? ¿Quién vino anoche al corredorcito? Ayer no estaba aquella como rajadura. ¿Quién? ¿Quién? ...

/ Ya tenia el invierno encima. Era imposible que en aquella duda de visitas nocturnas de gallinas y fantasmas que comian aguacate dejara su corredorcito sin su presencia durante todo el invierno. Vendría a ver llover alli donde el monte se traga el agua... / (p. 10). 
En este fragmento el DIL se da en forma de monólogo interior: es el pensamiento del protagonista que aflora. Conviene deslindar los planos sintácticos. La primera oración es el relato del autor; a continuación encerrado en cuatro interrogantes se da un monólogo interior en discurso directo (DD) para seguir después el mismo monólogo en $\mathrm{DIL}_{\mathrm{b}}$.

La diferencia puede notarse en el aspecto verbal y en los pronombres traspuestos. En discurso directo el monólogo en DIL sería asi: "Ya tengo el invierno encima. Es imposible que en esta duda deje mi corredorcito sin mi presencia durante todo el invierno."

Asturias trabaja su estilo con refinamiento. A poco que penetra en la narración y en la descripción minuciosa se introduce también en su personaje. Presenta al niño una y otra vez en ese corredorcito a la espera de algo inexplicable."

Entonces el alhajadito empieza a golpear un pilar para ver qué pasa. A los golpes escapan arañas, ratones y cucarachas: / ¿Como? . . ¿ ¿Había tanto ser vivo en aquel trecho de corredor del que él se consideraba único habitante? " (p. 13). [DIL $\mathrm{D}_{\mathrm{b}}$ ]

Se puede apreciar claramente el DIL como forma intermedia entre DD y DI. Comienza con una interrogación característica del DD. Sigue con otra; pero en ésta se advierte la trasposición del presente al imperfecto, el cambio del pronombre adjetivo "éste" por "aquel" y el cambio del pronombre sustantivo "yo" por "él" aparte del trueque de la forma pronominal "me" por "se". El autor irrumpe nuevamente ahora con una oración simple: "El fingido temblor sacaba familias enteras de cucarachas, arañas y ratones" (p. 13).

Y nuevamente el protagonista continúa su monólogo interior en DIL:

/ i Cuántos ojos, no sólo sus ojos. . ., gotitas de agua viva, luminosas gotitas de agua inteligente! ; Cuántos movimientos en la oscuridad! No sólo él se movía en el corredorcito. . . . . / iY él que creía estar solo y ser el único dueño del corredorcito!/ (p.13). $\left[\mathrm{DIL}_{\mathrm{b}}+\mathrm{DIL}_{\mathrm{b}}\right]$

Un tema recurrente en las páginas del libro es el de la muerte. El propio Asturias afirma el valor del tiempo en cuanto pasado y recuerdo. Para él la vida y la felicidad terrena quedan ancladas a la muerte y al recuerdo. ${ }^{7}$ De allí que uno de los motivos sea el del "charco del limosnero," una laguna, un campo-santo sin cruces en cuyo fondo se agitan esqueletos. El agua del charco es el impedimento que separa al hombre de la realidad. La primera vez que aparece en la obra el motivo del charco es justamente en un monólogo interior del alhajadito expresado en DIL:

/ El charco del limosnero. Desde el corredorcito no se alcanzaba a ver ni empinándose mucho, ni subiéndose a las bases de los pilares. Mejos si hubiera ido con los pescadores. Allá andaria con ellos, callado, oyendo el agua entre las linfas verdes, carnosas y florones morados y blancos como mariposas acuáticas. Allá flotaria pensando en el corredorcito / (p. 16). [DIL $\left.\mathrm{D}_{\mathrm{b}}\right]$

Nuevamente la narración corta el hilo del pensamiento, pero para indicarnos que es el protagonista el que piensa y no el autor que narra: 
De una manotada se espantó una mosca. No estaba comiendo caña. ¡Ah!, pero estaba pensando... El pensamiento es dulce, azucara los huesos de la cabeza y la cara, y las moscas gustan de su miel tan impalpable y tan presente. Con ademán lento se apartó las moscas (p. 16).

Otra vez el monólogo interior en DIL para encerrar el misterio y la sugerencia del protagonista:

$l_{¿}$ Por qué no podia estar simultáneamente en el charco del limosnero con los pescadores y en el corredorcito contemplando el entierro del alacrán? ... / (p. 16).

Presencia y ausencia. Ser y haber sido. Vejez y niñez. Estos contrastes se dan én la expresión estética de Asturias por un uso particular del recurso que nos ocupa. En $E l$ Alhajadito, hay frecuencia del DIL $_{\mathrm{b}}$. En esa forma el "punto de vista" o perspectiva del autor omnisciente va cambiando al personaje que manifiesta su mundo interior por un medio indirecto.

No es éste lugar para desarrollar tema tan complejo pero de paso queremos señalar una aproximación - valga el uso reiterado que ambos hacen de DIL - entre el Asturias de El Alhajadito y el García Márquez de Cien años de soledad. Ese engolosinamiento con las cosas viejas, abandonadas, fulgor de telarañas, papeles amarillos; esas escenas lugareñas de otros tiempos, tan hispanoamericanas, esa atracción por lo que fue y el ansia de que vuelvan a ser, aparecen en ambos autores.

En nuestra búsqueda de DIL los ejemplos acrecen. Asturias es insuperable en el estilo, gran señor de la lengua, del habla guatemalteca, con sus arcaísmos y su sabor a conseja indígena. No estamos seguros de que el novelista maneje a conciencia este recurso del DIL, pero consciente o no lo hace con sumo arte. Hay casos en que DIL aparece en una página, la 22 por ejemplo y después de seguir la narración salpicada con monólogos interiores en DD, el final del capítulo retorna en dos exclamaciones que son como una efusión, como un eco del DIL anterior porque esas exclamaciones no pertenecen ya al autor, que ha continuado el relato, sino al protagonista que las ha anticipado dos páginas antes:

/ Si encontrara en el corredor, en su corredorcito, la más mínima abertura para espiar tanto misterio. Una rendija en la que sólo cupiera un cabello... / ( p. 22).

Continúa la narración. Asturias se va mezclando paulatinamente al habla del alhajadito. Hasta que al fin surge el ansia de la rendija en el pilar: ${ }^{\star}$ i Una rendija! i Una rendija! ..."/ (p. 24).

Pero no faltan ejemplos de $\mathrm{DIL}_{\mathrm{a}} \mathrm{y}$ en este aspecto queremos señalar dos casos de DIL coral. Están ambos en el capítulo VII cuando desaparece un curioso personaje, el viejecillo del bastón:

Las criadas se santiguaban. / Todos los de aquella casa desaparecían... ¡Don dejó la mesa puesta...! jDon la cama ya hecha para acostarse! Uno de todos el salón lleno de invitados.../ (p. 26). 
Y más adelante en un cuadro de realismo mágico la servidumbre fantasmal oye pasos y se pregunta quién será:

Todo dormía. En el cielo nocturno, allá muy lejos empezaba a subir la luna... Como si regresaran del sueño la servidumbre fantasmal de indios trenzudos y criadas de carnes de caldo gordo, alcanzó a oir pasos en el zaguán... pasos con eco... Sabido es que los pasos de los muertos no producen eco... / ¿Quién sería...? / / ¿Quién regresaria a esas horas alli donde jamás, nunca, nadie regresó ...? / (p. 26).

En este microcontexto como en todo el libro alienta un verdadero goce de creación, "domina el profundo reclamo de la memoria, la atracción del mundo remoto de la infancia." 8

\section{Calculo de frecuencias}

El señor Presidente

260 págs. efectivas.

Promedio: 379 por página.

Palabras totales $=379 \times 260=98500$ aprox.

Casos de DIL contados en todo el libro $=47$.

Frecuencia $=\frac{38}{98500}=0,00048$, o sea 0,48 casos cada 1000 palabras.

En números redondos: un promedio de 1 caso de DIL cada 2000 palabras.

\section{El Alhajadito}

Promedio: 349 palabras por página.

126 páginas efectivas.

Palabras totales $=126 \times 349=43.974$ aprox.$=44.000$.

Casos de DIL contatos en todo el libro $=38$.

Frecuencia $=\frac{38}{44.000}=0,00086=0,86$ por cada 1000 palabras.

En número redondos: 1 caso cada 1200 palabras. ${ }^{9}$

Departamento de Letras

Universidad de Buenos Aires

Buenos Aires, Argentina 


\section{NOTAS}

${ }^{1}$ Marguerite Lips, Le style indirect libre (Paris: Payot, 1926).

${ }^{2}$ Friedrich Todemann, "Die erlebte Rede im Spanischen," Romanische Forschungen, XLIV, 1930.

${ }^{3}$ Miguel Angel Asturias, El señor Presidente, 14 . $^{\text {a }}$ ed. (Buenos Aires: Losada, 1970).

${ }^{4}$ Luis Harss, Los nuestros, 3. ${ }^{\mathrm{a}}$ ed. (Buenos Aires: Sudamericana, 1969), p. 101.

${ }^{5}$ Leo Spitzer, "L'originalità della narrazione nei 'Malavoglia',"Belgafor, I (1956), 38-53.

${ }^{6}$ Giuseppe Bellini, La narrativa de Miguel Angel Asturias (Buenos Aires: Losada, 1969).

${ }^{7}$ Miguel A. Asturias, El Alhajadito (Buenos Aires: Goyanarte, 1961).

${ }^{8}$ G. Bellini, op. cit., p. 189. Véase también Rev. Iberoamericana [Homenaje a Miguel Angel Asturias], n. ${ }^{\circ} 67$ (enero-abril 1969).

9 Para un método similar de cálculo de frecuencias consúltese Petrona D. de Rodriguez-Pasqués, El discurso indirecto libre en la novela argentina (Porto Alegre: PUC, 1975). 